\title{
Efeito antibacteriano e antiaderente in vitro do extrato da Punica granatum Linn. sobre microrganismos do biofilme dental
}

\author{
Jozinete V. Pereira ${ }^{1 *}$, Maria S. Vieira Pereira ${ }^{2}$, Fábio C. Sampaio ${ }^{3}$, Maria C. Correia \\ Sampaio $^{3}$, Pollianna M. Alves ${ }^{3}$, Cristina R. Ferreira de Araújo ${ }^{3}$, Jane S. Higino
}

\author{
${ }^{1}$ Departamento de Odontologia, Centro de Ciências Biológicas e da Saúde, Universidade Estadual da Paraíba, Rua \\ Juvêncio Arruda s/n, Campus Universitário de Bodocongó, 58.100-000, Campina Grande, PB, Brasil, \\ ${ }^{2}$ Departamento de Biologia Molecular, Centro de Ciências Exatas e da Natureza, Universidade Federal da Paraíba, \\ 58.059-900, João Pessoa, PB, Brasil, \\ ${ }^{3}$ Departamento de Odontologia Clínica Social, Centro de Ciências da Saúde, Universidade Federal da Paraíba, \\ 58.051-900, João Pessoa, PB, Brasil, \\ ${ }^{4}$ Departamento de Farmácia, Centro de Ciências e da Saúde, Universidade Federal de Pernambuco, Av. Arthur de \\ Sá s/n, 50.740-521, Recife, PE, Brasil
}

\begin{abstract}
RESUMO: Nesta pesquisa foi avaliada a atividade antimicrobiana e a capacidade de inibição da síntese de glucano in vitro do extrato da casca do fruto da romã (Punica granatum Linn.) sobre linhagens bacterianas de Streptococcus mitis, Streptococcus mutans, Streptococcus sanguis, Streptococcus sobrinus e Lactobacillus casei. Os ensaios foram realizados pelas técnicas de ágardifusão em placas para determinação da Concentração Inibitória Mínima (CIM) e técnica dos tubos inclinados para determinação da Concentração Inibitória Mínima de Aderência (CIMA) ao vidro, na presença de $5 \%$ de sacarose. Os mesmos procedimentos foram realizados com a clorexidina à $0,12 \%$. As CIMs $(\mathrm{mg} / \mathrm{mL})$ do extrato da $P$. granatum frente ao S. mitis, S. mutans, S. sanguis, S. sobrinus e $L$. casei foram 1:32, 1:8, 1:8, 1:512, e 1:128, respectivamente. Para as CIMAs o extrato da $P$. granatum mostrou resultados melhores que a clorexidina, exceto para o $S$. mutans com achados semelhantes na diluição de 1:256. Os resultados mostram a potencialidade da $P$. granatum na inibição do crescimento bacteriano e síntese de glucano representada pela aderência ao vidro, sugerindo o emprego do extrato da romã, como meio alternativo, no controle desses microrganismos na formação do biofilme.
\end{abstract}

Unitermos: Punica granatum, atividade antimicrobiana, efeito antiaderente, biofilme dental, Streptococcus.

\begin{abstract}
In vitro antibacterial and antiadherence effect of the extract of the Punica granatum Linn. upon dental biofilm microrganisms". In this study was evaluated the in vitro antibacterial activity and the inhibition of glucan sintesis of the fruit bark of Punica granatum Linn extract upon the following dental biofilm bacteria: Streptococcus mitis, Streptococcus mutans, Streptococcus sanguis, Streptococcus sobrinus and Lactobacillus casei. The tests were carried out by inundation tecniques in Petri dishes to determine the Minimum Inhibitory Concentration (MIC) and inclined tubes techniques to determine the Minimum Inhibitory Concentration of Adherence to glass (MICA) at the presence of $5 \%$ sucrose. Tests with gluconate of chlorexidine $(0.12 \%)$ were performed as controls. MICs of the P granatum extract dilutions $(\mathrm{mg} / \mathrm{mL})$ against S. mitis, S. mutans, S. sanguis, S. sobrinus e L. casei were 1:32, 1:8, 1:8, 1:512, and 1:128 respectively. For MICAs the $P$. granatum showed better results than chlorexidine, except for $S$. mutans with both substances showing similar results of 1:256. It can be concluded that the extract of the P. granatum has the potential to inhibit oral bacterial growth and glucan sintesis. The extract of the Punica granatum might be used as an effective antibacterial alternative agent against oral biofilm bacteria.
\end{abstract}

Keywords: Punica granatum, antibacterial activity, effect antiaderent, dental biofilme, Streptococcus.

\section{INTRODUÇÃO}

As mais prevalentes desordens dentais estão relacionadas com a cárie e doença periodontal, onde os microrganismos presentes no biofilme dental atuam como principais agentes responsáveis (Löe, 1978; Loesche,
1986; Pereira, 1999). A placa bacteriana tem sido definida como um biofilme de microrganismos, contidos em matriz orgânica formada por substâncias da saliva e da dieta do hospedeiro e por polímeros bacterianos (Gebara; Zardetto; Mayer, 1996; Marsh, 1992).

A formação do biofilme ocorre através de um 
processo ordenado e dinâmico onde há necessidade da fixação e proliferação de bactérias sobre as superfícies dos dentes (Addy; Slayne; Wade,1992); a aderência bacteriana à película adquirida representa um dos primeiros mecanismos envolvidos na iniciação do desenvolvimento do biofilme dental (Almeida, 2002; Gibbons, 1984; Liljemark; Schver; Bloomquist, 1978).

Devido a sua conduta contínua de agressão, o biofilme dental em cada etapa do seu desenvolvimento vai adquirindo novas espécies, dentre estas Streptococcus mitis, Streptococcus mutans, Streptococcus sanguis, Streptococcus sobrinus e Lactobacillus casei; que com sua patogenicidade irão provocar danos ao esmalte e tecido gengival (De Micheli; Sarian, 1990; Feist; De Micheli; Sarian, 1989; Kornman, 1986; Peres, 2003).

A remoção mecânica do biofilme é um fator importante na prevenção da cárie e doença periodontal. No entanto, existem dificuldades na remoção feita pelo próprio paciente (Addy; Slayne; Wade, 1992; De Paola, 1989; Stefani; Lima, 1996). Por se tratar de uma associação organizada, proliferante, enzimaticamente ativa, capaz de se aderir à superfície dos dentes, ocasionando alterações patológicas na cavidade bucal, é indicada sua desorganização tão logo quanto possível (Ciancio, 1992). Considerando a importância dessa desorganização e as dificuldades de manter os indivíduos motivados para realizar uma adequada limpeza da cavidade bucal, com o objetivo primário em termos de saúde bucal, que é controlar o acúmulo das bactérias sobre às estruturas dentárias, é válido e necessário associar aos procedimentos mecânicos também métodos químicos para o controle do biofilme dental (Castro, 2001; Cury, 1997; Mendes; Zenóbio; Pereira, 1995).

Inúmeras substâncias químicas vêm sendo pesquisadas, comoobjetivodeinibira formaçãodobiofilme dental, crescimento bacteriano, e consequentemente a adesão de microrganismos à superfície dentária (Kornman, 1986, Rodrigues Júnior, 1998). Dentre estas substâncias, atualmente se destacam os produtos de origem vegetal por se mostrarem potencialmente eficazes no que se refere à sua atividade antimicrobiana sobre várias espécies de microrganismos (Bhakuni et al., 1974; Gebara; Zardetto; Mayer, 1996).

Estudos sobre a ação anticariogênica de polifenóis extraídos de plantas têm sido relatados nas últimas décadas (Kakiuchi etal. 1996). Os extratos da romã, cajueiro, sanguinarina, tomilho e malva têm demonstrado ação antibacteriana e antiaderente in vitro, sobre os microrganismos Gram-positivos e Gram- negativos (Palenik et al. 1979; Naqvi; Khan; Vohora, 1991; Pessini et al., 2003; Michelin et al., 2005); os Streptococcus mutans, S. mitis, S. sanguis têm apresentado grande sensibilidade ao extrato da romã (Punica granatum) no que se refere ao crescimento e à capacidade de aderência sobre a superfície dental (Pereira, 1998).

A romanzeira, Punica granatum é uma planta da família Punicaceae, cultivada mundialmente em regiões de clima tropical e subtropical. Garcia (1992) afirmou que essa planta apresenta propriedades antiinflamatória e antibacteriana. Naqvi; Khan; Vohora, (1991) avaliaram a atividade antimicrobiana do extrato de Punica granatum sobre microrganismos Gram-positivos e leveduras, confirmando a presença de princípios ativos antimicrobianos na casca do fruto.

Assim sendo, o propósito deste estudo foi verificar in vitro a ação antibacteriana do extrato da Punica granatum, e analisar a capacidade de inibição da síntese de glucano frente as linhagens bacterianas de Streptococcus mitis, S. mutans, S. sanguis, S. sobrinus e Lactobacillus casei presentes no biofilme supragengival.

\section{MATERIAL E MÉTODOS}

\section{Material botânico e obtenção da matéria prima}

A matéria prima (fruto) da Punica granatum foi obtida de origem diversa, no mercado público central de João Pessoa - PB e identificado botanicamente no Laboratório de Toxicologia do Departamento de Ciências Farmacêuticas da UFPE (Universidade Federal de Pernambuco - Recife). Os frutos foram lavados com água e posteriormente separados em casca e mesocarpo, sendo a casca o material a ser utilizado na pesquisa. Em seguida a casca foi levada à secagem, em estufa a $33^{\circ} \mathrm{C}$ durante uma semana, para eliminação de umidade e estabilização do conteúdo enzimático. Passado este período o material foi retirado da estufa, triturado a pó em moinho elétrico e então submetido ao processo de extração dos princípios ativos.

\section{Extração}

O método de extração empregado foi a lixiviação ou percolação em fluxo contínuo à temperatura ambiente. Por se tratar de uma matéria rica em polifénois de fácil modificação estrutural, não foi utilizada a extração à quente, preservando assim a estabilidade do material. Na lixiviação em fluxo contínuo utilizou-se um processo onde existe a renovação constante da solução extratora (solução hidroalcoólica a $80 \% \mathrm{v} / \mathrm{v}$ ) durante um período de 24 horas. Decorrido este tempo o marco fica completamente esgotado. Nesta etapa, foram utilizados aproximadamente 8 litros de solução hidroalcoólica para $1 \mathrm{Kg}$ de matéria prima seca e pulverizada, visando o completo esgotamento da droga. Recuperou-se um volume de aproximadamente $6.600 \mathrm{~mL}$ do extrato que, após filtração para retirada de resíduos sólidos, foram acondicionados em frascos âmbar, limpos, secos e estocados em câmara fria.

\section{Concentração do extrato}

A etapa seguinte foi a concentração da solução em nível de extrato fluido 1:1 (p/v). O procedimento para 
Tabela 1. Concentração Inibitória Mínima em meio sólido do extrato hidroalcoólico de Punica granatum (EB) sobre Streptococcus mitis, Streptococcus mutans, Streptococcus sanguis, Strepcoccus sobrinus e Lactobaccillus casei.

Linhagens Bacterianas

Diâmetro do halos de inibição (mm)

Concentração do Extrato (EB; mg/mL)

\begin{tabular}{lccccccccccc} 
& EB & $1: 2$ & $1: 4$ & $1: 8$ & $1: 16$ & $1: 32$ & $1: 64$ & $1: 128$ & $1: 256$ & $1: 512$ & $1: 1024$ \\
\hline Streptococcus mitis & 25 & 23 & 21 & 19 & 16 & 15 & 0 & 0 & 0 & 0 & 0 \\
Streptococcus mutans & 20 & 18 & 14 & 11 & 0 & 0 & 0 & 0 & 0 & 0 & 0 \\
Streptococcus sanguis & 21 & 20 & 17 & 14 & 0 & 0 & 0 & 0 & 0 & 0 & 0 \\
Streptococcus sobrinus & 24 & 22 & 22 & 22 & 20 & 20 & 17 & 13 & 13 & 12 & 0 \\
Lactobacillus casei & 22 & 18 & 15 & 12 & 12 & 12 & 11 & 10 & 0 & 0 & 0 \\
\hline
\end{tabular}

$\mathrm{EB}=$ Extrato Bruto

Tabela 2. Concentração Inibitória Mínima em meio sólido do gluconato de clorexidina a $0,12 \%$ sobre Streptococcus mitis, Streptococcus mutans, Streptococcus sanguis, Strepcoccus sobrinus e Lactobaccillus casei.

Diâmetro do halos de inibição (mm)

Linhagens Bacterianas Concentração do Gluconato de Clorexidina à $0,12 \%$

\begin{tabular}{lccccccccc} 
& SD & $1: 2$ & $1: 4$ & $1: 8$ & $1: 16$ & $1: 32$ & $1: 64$ & $1: 128$ & $1: 256$ \\
\hline Streptococcus mitis & 18 & 16 & 14 & 12 & 10 & 0 & 0 & 0 & 0 \\
Streptococcus mutans & 18 & 18 & 17 & 14 & 14 & 0 & 0 & 0 & 0 \\
Streptococcus sanguis & 20 & 18 & 15 & 14 & 12 & 0 & 0 & 0 & 0 \\
Streptococcus sobrinus & 24 & 24 & 23 & 20 & 17 & 10 & 0 & 0 & 0 \\
Lactobacillus casei & 23 & 22 & 21 & 19 & 17 & 15 & 12 & 10 & 0 \\
\hline
\end{tabular}

$\mathrm{SD}=$ Sem Diluição

Tabela 3. Concentração Inibitória Mínima de Aderência (CIMA) do extrato hidroalcoólico de Punica granatum Linn. (EB) e gluconato de clorexidina a $0,12 \%$ sobre Streptococcus mitis, Streptococcus mutans, Streptococcus sanguis, Strepcoccus sobrinus e Lactobaccillus casei.

Linhagens Bacterianas

Streptococcus mitis

Streptococcus mutans

Streptococcus sanguis

Streptococcus sobrinus

Lactobacillus casei
Extrato hidroalcoólico de Punica granatum (CIMA)
Gluconato de Clorexidina 0,12\%

$\begin{array}{lc}1: 512 & 1: 128 \\ 1: 256 & 1: 256 \\ 1: 128 & 1: 64 \\ 1: 256 & 1: 16 \\ 1: 1.024 & 1: 64\end{array}$

a concentração do extrato foi realizado em evaporador rotatório (Modelo Ika-Werk), a uma temperatura constante de $45^{\circ} \mathrm{C}$. $\mathrm{O}$ extrato obtido apresentou um $\mathrm{pH}$ ligeiramente ácido, em torno de 4,74.

Os procedimentos de extração e concentração dos extratos hidroalcoólicos foram realizados no Laboratório de Tecnologia Farmacêutica (LTF) da Universidade Federal de Pernambuco (UFPE).

\section{Linhagens bacterianas}

16(1):jan/mar. 2006
Utilizou-se no presente trabalho linhagens bacterianas padronizadas de Streptococcus mitis (ATCC 9811), Streptococcus mutans (ATCC 25175), Streptococcus sanguis (ATCC 10557), Streptococcus sobrinus (ATCC 27609) e Lactobacillus casei (ATCC 7469), obtidos mediante solicitação na Fundação Tropical de Pesquisas e Tecnologia "André Tozello" (Campinas $\mathrm{SP})$ e Instituto Adolfo Lutz - SP, respectivamente.

\section{Determinação da atividade antimicrobiana do extrato hidroalcoólico de Punica granatum}


A atividade antimicrobiana em placas foi determinada pelo método de difusão em meio sólido para a determinação da Concentração Inibitória Mínima (CIM) do extrato de Punica granatum, sobre as linhagens bacterianas. As linhagens foram cultivadas em caldo nutritivo (BHI - Brain Hear Infusion - DIFCO). Foram realizadas perfurações no meio de cultura (Agar Müeller Hinton - DIFCO) de aproximadamente $6 \mathrm{~mm}$ de diâmetro. Nos orifícios foram colocados um volume de $50 \mu 1$ da solução do extrato diluída, variando da diluição $1: 1$ a 1:1024. As placas foram incubadas em estufa bacteriológica a $37^{\circ} \mathrm{C}$ em microaerofilia, por um período de 24 horas. Foram realizados estudos comparativos com a clorexidina a $0,12 \%$; os ensaios foram feitos em duplicata frente a cada linhagem ensaiada. A CIM foi considerada como a menor concentração do extrato que inibiu completamente o crescimento bacteriano, ou seja, presença do halo de inibição.

\section{Determinação da Concentração Inibitória Mínima de Aderência (CIMA)}

A concentração Inibitória Mínima de Aderência (CIMA) da bactéria ao vidro foi determinada na presença de sacarose a 5\%, usando-se concentrações crescentes e dobradas da solução diluída do extrato, variando de 1:1 a 1:1024. A partir do crescimento "overnight", as linhagens foram sub-cultivadas a $37^{\circ} \mathrm{C}$ em caldo Müeller-Hinton (DIFCO), em microaerofilia, por um período de 24 horas obtendo-se um inóculo de $10^{6} \mathrm{UFC} / \mathrm{ml}$. A incubação foi feita a $37^{\circ} \mathrm{C}$ por 24 horas em microaerofilia, com os tubos inclinados a $30^{\circ}$. A CIMA foi definida como a menor concentração do extrato em meio com sacarose que impediu a aderência bacteriana ao tubo de vidro.

\section{RESULTADOS E DISCUSSÃO}

Vários agentes antimicrobianos vêm sendo estudados, com o objetivo de inibir ou reduzir a formação do biofilme dental, crescimento bacteriano, e consequentemente a adesão de microrganismos à superfície dentária (Kornman, 1986; Moran et al., 2001; Rodrigues Júnior et al., 1998).

Nas últimas décadas, os fitofármacos têm assumido um papel importante como meio terapêutico alternativo na odontologia, mediante as suas propriedades antimicrobianas frente às afecções bucais, principalmente as decorrentes do biofilme dental (Bhakuni, et al., 1974; Gebara; Zardetto; Mayer, 1996; Pereira, 1998). Akpata e Akinrimisi (1977) afirmam que o extrato aquoso de plantas inibe o crescimento de Streptococcus mutans no biofilme dental, patógeno altamente responsável pela formação de cárie.

Kakiuchi et al. (1986), Cáceres (1987), Naqvi et al. (1991), Anesini e Perez (1993), afirmaram que a Punica granatum possui ação antimicrobiana especíica sobre bactérias presentes no biofilme supragengival, produzindo uma interferência na síntese de poliglicanos, agindo, então, no mecanismo de aderência das bactérias sobre as superfícies dos dentes. Como a aderência bacteriana tem sido mostrada como sendo um dos primeiros mecanismos envolvidos na iniciação do desenvolvimento do biofilme dental, a inibição desse processo, certamente, conduzirá a um efetivo controle qualitativo do mesmo.

No presente estudo, buscou-se verificar a ação do extrato hidroalcoólico de Punica granatum sobre espécies de microrganismos aeróbios predominantes no biofilme supragengival; Streptococcus mitis, S. mutans, $S$. sanguis, S. sobrinus e Lactobacillus casei. Os resultados demonstram a eficácia do extrato da romã sobre as linhagens ensaiadas. Todas as linhagens são sensíveis ao extrato hidroalcoólico de Punica granatum. Observou-se halos de inibição que variaram de 10 a $25 \mathrm{~mm}$, sendo considerado ativo o extrato que mostrou halos de inibição superior a $15 \mathrm{~mm}$. A inibição do crescimento apresentouse homogênea, de acordo com o grau de concentração do extrato hidroalcoólico da planta em estudo. Houve uma diminuição proporcional do diâmetro dos halos, a medida que concentração do extrato foi diminuída, conforme apresentado na Tabela 1.

Com relação à clorexidina observamos resultados semelhantes com uma proporcionalidade entre diminuição do diâmetro dos halos de inibição e a diminuição da concentração da substância (Tabela 2).

A clorexidina tem sido muito utilizada no controle de formação do biofilme dental, age alterando a composição bacteriana do biofilme supragengival produzindo uma redução significante sobre o número de Streptococcus mutans por períodos prolongados. Segundo Beighton; Decker; Homer (1991) este fato ocorre devido à sua liberação lenta na cavidade bucal, e consequentemente a sua ação inibidora sobre as enzimas glicosídicas e proteolíticas.

O biofilme dental é essencial na patogênese da cárie dental e constitui o maior fator etiológico na gengivite crônica (Addy; Slayne; Wade, 1992). A presença de polissacarídeos extracelulares é de extrema importância na fase inicial do processo de formação do biofilme, pois os mesmos favorecem ao mecanismo de aderência intermicrobiana de Streptococcus mutans e $S$. sobrinus (Ikeno; Ikeno; Miyazawa, 1991; Siegrist et al., 1986).

A adesão das bactérias às superfícies orais constitui um processo complexo multifatorial, influenciado pelo ambiente, superfície da célula bacteriana e a superfície do substrato.

O mecanismo de aderência das bactérias sobre as superfícies dos dentes envolve adesinas presentes na membrana da célula bacteriana e receptores específicos localizados na película adquirida. Vários fatores estão associados a esse mecanismo, dentre estes, a interação de proteínas, adesinas, lecitinas e interações hidrofóbicas representam um papel importante nesse processo (Gibbons, 1984). Desta forma, a interferência 
com a adesão bacteriana nas superfícies dos dentes pode ser um caminho para se obter o controle da placa, e consequentemente previnir a instalação de patologias bucais.

Poucos estudos relatam a influência dos agentes antimicrobianos nos estágios iniciais de formação do biofilme, especialmente com relação a seu efeito sobre os fatores envolvidos na aderência bacteriana à película adquirida (Cai et al., 1994, Van Loveren; Buijs; Ten Cate, 2000).

Neste estudo o extrato de Punica granatum foi efetivo na inibição da aderência das cinco linhagens representada pela ausência de aderência ao vidro na presença de sacarose (Tabela 3). Estes resultados são concordantes com os observados por Kakiuchi et al. (1986), que realizaram um estudo relacionado à atividade antimicrobiana de plantas, tais como Galla rhois e Punica granatum. Estas plantas produzem um efeito inibitório que interfere na síntese do glucano pela glucosiltransferase, produzido pelo Streptococcus mutans que, consequentemente, irá intervir no mecanismo de aderência deste microrganismo sobre as superfícies dos dentes.

O estudo comparativo da ação do extrato da Punica granatum com o gluconato de clorexidina, revelou uma maior atividade de inibição de síntese de glucano pelo extrato da romã (Tabela 3 ). Os resultados são bastante promissores uma vez que os microrganismos neste estudo são os maiores responsáveis pela formação do biofilme dental.

\section{CONCLUSÕES}

Os resultados obtidos neste estudo mostram a importância das indicações terapêuticas das plantas medicinais como método alternativo e de baixo custo na clínica odontológica, uma vez que o extrato hidroalcoólico da casca do fruto da romã apresenta potencial atividade antimicrobiana sobre os microrganismos presentes no biofilme supragengival, como também demonstra, in vitro, inibição da aderência bacteriana na superfície, fator predisponente para o desenvolvimento da cárie e doenças periodontais.

\section{REFERÊNCIAS}

Addy M, Slayne MA, Wade WG 1992. The formation and control of dental plaque - an overview. J Appl Bacteriol 73: 269-278.

Akpata ES, AkinrimisI EO 1997. Antibacterial activity of extracts from some Africans chewing stticks. Oral Surg 717-722.

Almeida PF 2002. Microbióta estreptocócica associada com a formação inicial da placa dental. Revista de Ciências Médicas e Biológicas 1: 33-41.

Anesini C, Perez C 1993. Screening of plants used in Argentine folk medicine for antimicrobial activity. $J$ Ethnopharmacol 39: 119-128.
Beighton D, Decker J, Homer KA 1991. Effects of chlorhexidine on proteolytic and glicosidic enzyme activities of dental plaque bacteria. J Clin Periodontol 18: 8589.

Bhakuni DS 1974. Screening of Children plants for antimicrobial activity. $J$ Nat Prod 37: 621-623.

Cáceres A 1987. Screening of antimicrobial activity of plants popularly used in Guatemala for the treatment of dermatomucosal diseases. J Ethnopharmacol 20: 223-237.

Cai S, Simionato MRL, Mayer MPA, Novo NF, Zelante F 1994. Effects of subinhibitory concentrations of chemical agents on hydrophobicity and in vitro adherence of Streptococcus mutans and Streptococcus sanguis. Caries Res 28: 335-341.

Castro SL 2001. In vivo study efficacy of antiseptics on microaerobic microorganisms of the oral cavity. Rev Dent 1: 1-9.

Ciancio SG 1992. Agents for the management of plaque and gingivitis. J Dent Res 71: 1450-1454.

Cury JA 1997. Controle químico da placa dental. In: Kringer, L.(coord). Promoção de Saúde Bucal. São Paulo: ABOPREV/ Artes Médicas, cap. 7, p.131-140.

De Micheli G, Sarian R 1990. Placa bacteriana: controle químico; estudo clínico em humanos da eficiência de dois produtos, comparados com um placebo, quando utilizados na forma de bochechos imediatamente antes da higiene bucal (pré-escovação). Rev APCD 44: $333-336$

De Paola LG 1989. Inibição quimioterapêutica no desenvolvimento da placa dentária e gengivite. $J$ Clinic Periodontol 16: 311-315.

Feist IS, De Micheli G, Sarian R 1989. Clorexidina: prós e contras da sua utilização em periodontia. Revista APCD 43: 102-109.

Garcia AA 1992. La terapeutica com plantas medicinales: fitoterapia - vademecum de prescripcion, Bilbao: cita Publicaciones: 175.

Gebara ECE, Zardetto CGDC, Mayer MPA 1996. Estudo in vitro da ação antimicrobiana de substâncias naturais sobre S. mutans e S. sobrinus. Rev Odontol Univ São Paulo 10: 251-256.

Gibbons RJ 1984. Microbial ecology. Adherent interactions which may affect microbial ecology in the mouth. J Dent Res 63: 378-385.

Ikeno K, Ikeno T, Miyazawa C 1991. Effects of propolis on dental caries in rats. Caries Res 25: 347-351.

Kakiuchi N 1986. Studies on dental caries prevention by traditional medicines. VIII. Inhibitory effect of various tannins on glucan synthesis by glucosyltransferase from Streptococcus mutans. Chem Pharm Bull 34: 720-725.

Kornman KS 1986. The role of supragingival plaque in the prevention and treatment of periodontal diseases: a review of current concepts. J Periodont Res (Suppl.): 5-22.

Liljemark WF, Schaver SV, Bloomquist CG 1978. Compounds which affect the adherence of Streptococcus sanguis and Streptococcus mutans to hydroxyapatite. J Dent Res 57: 373-379.

Löe H 1978. Controle de placa na doença periodontal. RGO 2: 28-31.

Loesche WJ 1986. Role of Streptococcus mutans in human 
dental decay. Microbiol Rev 50: 353-380.

Marsh PP 1992. Microbiological aspects of the chemical control of plaque and gingivitis. J Dent Res 71: 14311438.

Mendes MMSG, Zenóbio EG, Pereira OL 1995. Agentes químicos para o controle de placa bacteriana. Rev Periodont 253-256.

Michelin DC, Moreschi PE, Lima AC, Nascimento GGF, Paganelli MO, Chaud MV 2005. Avaliação da atividade antimicrobiana de extratos vegetais. Rev Bras Farmacogn 15: 316-320.

Moran J, Addy M, Newcombe RG, Marlon I 2001. A Study to assess the plaque inhibitory action of newly formulated triclosan toothpaste. J Clin Periodontal 28: 86-89.

Naqvi SAH, Khan MSY, Vohora SB 1991. Anti-bacterial, antifungal and anthelmintic investigations on indian medical plants. Rev Fitoterapia 62: 221-228.

Palenik CJ, Park K, Katz S, Stook GK 1979. Efects of water sduble components derived from cocoa on plaque formation. J Dent Res 58: 1749.

Pereira CV 1999. Ação de amostras de Streptococus mutans e Streptococus sobrinus sobre diferentes carboidratos com ênfase dentária - Estudo in vitro. Rev Passo Fundo 4: 33-39.

Pereira JV 1998. Atividade antimicrobiana do extrato hidroalcoólico da Punica granatum Linn. sobre microrganismos formadores de placa bacteriana. João Pessoa, 92p. Dissertação de Mestrado, Centro de Ciências da Saúde, Universidade Federal da Paraíba.

Peres DHDF 2003. Prevalência dos Streptococus do grupo mutans (Egm) em crianças de 8 a 60 meses nas creches da cidade de Joinville - SC. J. Bras Odontopediat Odontol Bebê 6: 36-40.

Pessini GL, Holetz FB, Sanches NR, Cortez DAG, Dias-Filho BP, Nakamura CV 2003. Avaliação da atividade antibacteriana e antifúngica de extratos de plantas utilizados na medicina popular. Rev Bras Farmacogn 13(Supl 1): 21-24.

Rodrigues Júnior AL 1998. Redução do índice de placa com listerine. Avaliação do índice de placa em relação ao uso de listerine e/ou escovação.RGO 46: 101-108.

Siegrist BE, Gusberti FA, Brecx MC, Weber HP, Lang NP 1986. Efficacy of supervised rinsing with chlorhexidine digluconate in comparison to phenolic and plant alkaloid compounds. J Periodontol Res 60-73.

Stefani CM, Lima AFM 1996. Avaliação dos efeitos clínicos da aplicação de gel de clorexidina em pacientes sob tratamento ortodôntico. Rev Periodontia 5: 300305.

Van Loveren C, Buijs JF, Ten Cate JM 2000. The effect of triclosan toothpaste on enamel demineralization in a bacterial demineralization model. J Antimicrob Chemoth 45: 153-158.

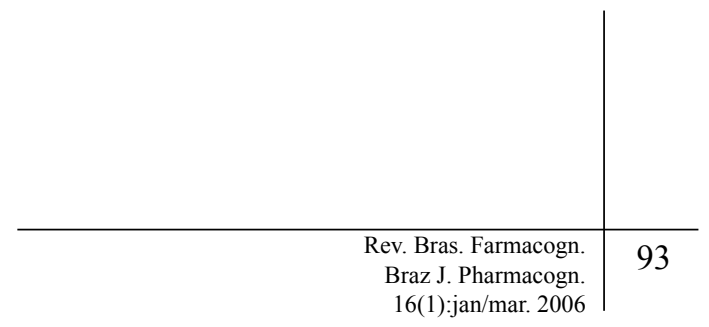

